\title{
The role of distance education in the learning process in a university
}

\author{
Lyubov Khoronko ${ }^{1}$, and Ekaterina Bondarenko ${ }^{2 *}$ \\ ${ }^{1}$ Don State Technical University, 344000, Rostov-on-Don, Russia \\ ${ }^{2}$ Volgograd State Medical University, 400131, Volgograd, Russia
}

\begin{abstract}
The article analyses the possibilities of a distance learning system for organizing the educational process in a medical university. It also considers the possibilities of independent work of students in the distance learning system. The article describes the options for using situational tasks as a form of independent work of medical university students. A situational task as a form of organizing independent work implements several educational goals. The situational task results in strengthening and systematizing knowledge, developing skills for self-organization, selfdevelopment, self-assessment, self-analysis in the learning process; and it can also result in developing critical thinking skills. The article deals with the functions of a teacher organizing the learning process, various forms of independent work, managing and supervising the work of students, and giving consultations on problematic issues, if necessary.
\end{abstract}

\section{Introduction}

With the entry into force of the new federal state educational standards of higher professional education, there was a redistribution of the academic load: the number of classroom hours reduced and the time for independent work increased. Increasing the number of hours for independent work in the curricula of disciplines in higher educational institutions is our reality.

The leading role of the independent work of students in the modernization of the learning process is reflected in the order of the Government of the Russian Federation. According to this order, by 2020, all students will study based on individual curricula, which include a significant part of independent work using information technology.

Therefore, the introduction and widespread use of simulation-based, e-learning and distance learning are becoming a priority in the organization of the modern educational process, including the preparation of educational practices in a distant format.

The implementing of distance learning makes the learning process more accessible in terms of place, time, and pace of learning (implementation of an individual educational trajectory).

When organizing distance learning [1,2], a significant role is given to independent work. This is important both in the process of training students of medical universities and in the future in the refresher training courses.

\footnotetext{
* Corresponding author: moni-moni@yandex.ru
} 
It is especially important to organize independent work $[3,4]$ in a distant format in the context of the spread of the COVID-19 coronavirus infection in 2020.

\section{Materials and Methods}

Currently, the educational process in the context of the transformation of medical education should be focused on the formation of self-improvement skills and self-education. The key task of medical professional education is to enable the student to gain not only medical knowledge but also to form the skills for independent activity and to be up-to-date throughout life, i.e. "lifelong education".

Independent work, organized in a medical university, includes working on various issues within the framework of the discipline being studied; performing tasks in the laboratory and practical classes; preparing for intermediate and final assessment; taking practices and completing tasks within the practice report. Independent work at the university $[5,6]$ is considered to be a form of medical students training for educational practices. When solving professional tasks within the organization of the independent work of the student, theoretical knowledge will be formed, which will help to master practical skills.

\section{Results and Discussion}

The analysis of the research showed that with the help of independent work, it is possible to implement the stimulating, organizational, research, developing, orientate and regulatory functions of the educational process.

The stimulating function of independent work is aimed at finding several possible solutions to the problem and choosing the optimal way to solve it. The formation of the skill of collecting and analyzing educational material when working with large amounts of information is a developing function of independent work. The development of selfeducation skills, the stimulation of cognitive activity skills in solving professional tasks reflects the organizational function of independent work. The formation of self-assessment skills and reflexive evaluation activities provides the regulatory function of independent work.

The analysis of the curriculum allowed us to determine the share of independent work of the student (see Fig. 1).

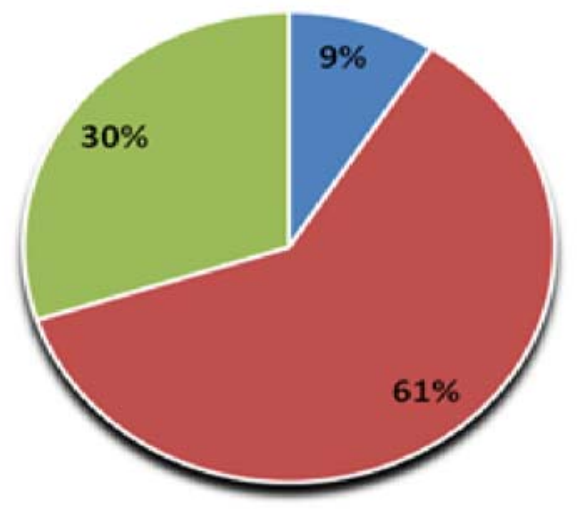

- Exams

- Classroom classes

= Independent work

Fig. 1. Distribution of training load. 
At the moment the share of independent work of students of the specialty "General Medicine" is $30 \%$. The share of classroom teaching load (lectures and practical lessons) is $61 \%$; the exams account for $9 \%$ of the total academic load.

A situational task can be considered as a means of organizing independent work $[7,8]$ within the process of mastering theoretical disciplines. The situational task serves as a means of training medical students to solve standard problems in the course of educational practices, both in the traditional form of learning and in the distance format.

If we consider the situational task $[9,10]$ as a form of organizing independent work, we can distinguish the following several goals. The use of situational tasks in the educational process consolidates and systematizes knowledge in a particular discipline, develops the ability to mobilize existing knowledge to obtain new ones.

The educational purpose of applying situational tasks is related to the forms and methods of teaching and its content. The realization of the educational goal occurs through the formation of positive motivation for learning. At the same time, in the course of solving situational tasks, comprehensive development of the student's personality takes place. The developing function of the situational tasks [11] is realized through the formation of skills for self-organization, self-development, self-assessment and self-analysis. Case studies in the educational process of a medical university are aimed at the formation of skills, the development of critical thinking, to prevent mistakes in future professional activities. The leading methodological material is a situational task, which includes conditions, a description of the case, initial data, and a question-task set before the student. A situational task must contain all the necessary data to solve it, if there is no data, then the conditions from which this data can be extracted. Based on the reproductive, productive and creative levels of independent work, we will highlight the forms of independent work implemented through situational tasks. At the first level, which is the reproductive level, there is a solution for tasks and cases. The second level is associated with the solution for case studies aimed at developing the skills of analysis and selection of material, the skills of systematization and classification. The third level provides the formation of skills for independent setting of research tasks, critical thinking skills, and research activity skills.

The situational task as a form of training medical university students to solve standard problems in the course of educational practices allows integrating the development of theoretical positions with the mastery of practical aspects of the studied material of the discipline. The method of case-study analysis or case method is widely used in the practice of medical education.

When working on case studies, let us consider the mistakes that can be made by both students and teachers.

Error 1. The deficiency of the stage for analyzing the statement of the problem.

The first step is to read the statement of the task. It is important to carefully read the statement of the task and highlight the key aspects necessary to solve it. Often this stage is not present when solving cases, but there are students in the group for whom this stage is important. Most students can quickly pass this stage and move on to solving the case, the main function of the teacher is to help those students who need this stage. To be able to independently analyze the statement of the task, several auxiliary questions are proposed to help solve the case step by step.

Error 2. The deficiency of the stage of finding a solution.

When solving situational tasks, the student is offered several questions, answering which students can come to the right decision. When passing over this stage, the skill training of analytical activity, the reflexive-evaluative stage, often there are difficulties in formulating the correct answer, solving the task. Students with well-developed analytical skills should be offered cases for composing tasks based on reference data, tasks with redundant data.

Error 3. The deficiency of stage for choosing ways to solve the task. 
This stage is necessary for analyzing possible ways to solve the task, determining the only correct solution. This skill allowed gaining experience in solving case studies, training the skill of working according to an algorithm or a pre-planned plan.

Error 4. It is important to identify the maximum number of relations between the components of the statement for analyzing correctly the statement of the task and coming to one of several possible options. If one of the components of the task statement was omitted or not analyzed during the analysis of the statement, this may lead to an incorrect solution to the task or the wrong decision.

Error 5. Formulation of special questions.

It is important to stimulate students' mental activity when formulating additional questions. Questions-hints can lead to a quick answer and precisely correct. It is necessary to ask questions so that several possible solutions arise at once, during the discussion of which all solutions will be analyzed.

Possible errors of students during the training practices will have differences due to the specifics of professional training. The generalized typology of errors inherent in students of different specialties when taking educational practices and, accordingly, the typology of educational case studies for their prevention can be presented in this way.

Violation of the algorithm for solving standard situational tasks by students

When studying theoretical material in practical classes, it is important to repeat frequently the sequence of necessary actions, to create learning situations using the "aquarium" technique, case study technologies (practice-oriented tasks, including the analysis of options for incorrect medical care), to develop critical thinking, problem-based learning, storytelling, to organize reflexive and evaluative activities of students.

In the course of training practices, daily analysis of the actions performed, in case of incorrect completing or difficulties - search for the reasons, individual plan to prevent mistakes, constant individual and group reflection.

Violations in the process of communication with patients

In practical classes, it is important to analyze the situation of student-patient interactions based on the provisions of medical ethics and deontology, to give the tasks for making dialogue with the patient (for example, to explain to the patient how to prepare for a specific procedure), to play professional situations, for example, to conduct micro-surgery, acting both as a patient and as a medic. Also, it is advisable to make a video recording of the roleplaying and a collective analysis of successful and unsuccessful communication options.

During training practices, in the practice diary, it is recommended to record communication with patients with an explanation - whether it was possible to establish contact, what difficulties arose, how they were overcome, what barriers arose in communication, which approaches in interacting with the patient was the most successful. In the process of group reflection, it is important to emphasize each time that incorrect communication leads to a lack of trust on the part of the patient, which may result in a professional error, since the patient may not inform the doctor in a timely about the change in his/her state of health.

\section{Violations in the process of communication with colleagues}

Taking training practices allows the student to understand that success in medicine is due to the professional teamwork. Building communication with colleagues - junior and secondary medical staff, doctors, classmates - in the role of a practising physician can be difficult for some students. The theoretical knowledge, consisting of a respectful attitude towards everyone and the understanding that students are not professionals, but only learners, and if there is an unclear situation to seek help from more knowledgeable colleagues is the norm, is implemented in practice. Any violation affects the quality of work, and if the medical history does not describe the change in the patient's condition and a colleague who comes on duty will be guided by it, then an error is possible. Personal and collective responsibilities 
are discussed in group reflection. The implementation of project tasks, including in the research part of the practice, contributes to the development of teamwork skills.

It should be noted that independent work arranged within the educational process is organized and performed under the precise supervising of the teacher [12, 13].

What are the functions of the teacher in the organization of the educational process in the distance format?

1) Teacher-organizer. He/She organizes effective interaction between "student-teacher", "student-student", directing the educational process to achieve goals.

2) Teacher-manager.

3) Teacher-tutor. The teacher organizes, manages and controls the educational process. At the preparatory stage, the teacher develops the syllabus of the discipline, where the leading role belongs to independent work. The syllabus can include lectures, workbooks, a bank of multiple-choice tasks, a dictionary of key concepts, individual tasks for independent work, cases, situational tasks, etc. The teacher organizes individual educational routes taking into account the abilities, level of preparation and motivation of students. The organization of group and individual consultations adjusts the work of students; target them for achieving educational goals. The organization of the reflexive evaluation stage ensures the formation of students' skills of self-analysis and self-assessment of the effectiveness of independent learning activities $[14,15]$.

\section{Conclusion}

It is also worth pointing out the difficulties that arise when organizing independent work in a remote format. Firstly, human and time resources aimed at creating a variety of tasks and presenting them in electronic form; secondly, the development of precise criteria for evaluating objectively the completed tasks; and, thirdly, the reduction of communication skills. But, despite some difficulties, the correct organization of independent work in the process of distance learning implements the possibilities of an individual trajectory of student learning, learning at a convenient time, in any place, taking into account the individual capabilities of students, which can significantly improve the quality of educational training.

\section{References}

1. R.D. Costa, G.F. Souza, R.A.M. Valentim, T.B. Castro, Cognitive Systems Research 64, 134-145 (2020) doi.org/10.1016/j.cogsys.2020.08.004.

2. O.T. Arulogun, et al., Survey dataset on open and distance learning students' intention to use social media and emerging technologies for online facilitation, Data in Brief (Aug, 31). 105929 (2020)

3. S.J. Kang, M.H. Chong, L. Hyerim, The impact of virtual simulation on critical thinking and self-directed learning ability of nursing students, Clinical Simulation in Nursing. (2020) doi.org/10.1016/j.ecns.2020.05.008.

4. N.A. Kovalenko, A.Y. Smirnova, Procedia-Social and Behavioral Sciences 166, 393398 (2015)

5. T. Ohsawa, T. Shimazoe, Journal of the Pharmaceutical Society of Japan 137(8), 947956 (2017). https://doi:10.1248/yakushi.17-00001-4.

6. Z.I. Almarzooq, M. Lopes, A. Kochar, Virtual learning during the COVID-19 pandemic, a disruptive technology in graduate medical education. 2635-2638 (2020)

7. X. Eshonkulov, The problem of reasoning of students' occupancy in independent work in higher education institutions, JSPI. (2020) 
8. E. Zhestkova, N. Fomina, Electronic Information and Educational Environment of the University as a Means of Organizing Independent Work of Students. Environment. technologies. Resources, Proceedings of the International Scientific and Practical Conference 2, 247-252 (2019)

9. Z. Ozdilek, Journal of Baltic Science Education 13(5), 695 (2014)

10. I. Popil, Nurse education today 31(2), 204-7 (2011) doi:10.1016/j.nedt.2010.06.002.

11. T. Ryall, et al., Journal of multidisciplinary healthcare 9, 69-82 (2016) doi:10.2147/JMDH.S92695.

12. A.M. Kaihlanen, L. Salminen, M. Flinkman, \& E. Haavisto, Collegian 26(1), 55-61 (2019) doi.org/10.1016/j.colegn.2018.03.003.

13. N.G. Lederman, J.S. Lederman, J Sci Teacher Educ. 27, 693-696 (2016) doi.org/10.1007/s10972-016-9486-Z

14. M. Nurgaliyeva, A. Auyezova, A. Kosmuratova, Revista de Ciencias Humanas y Sociales 85, 290-307 (2018)

15. M. Paric, A.M. Kaihlanen, T. Heponiemi, \& K. Czabanowska, Nurse Education Today 99, 104787 (2021) doi.org/10.1016/j.nedt.2021.104787. 